\title{
Diagenesis of benthic foraminifera: Fluid penetration and isotopic exchange visualized with NanoSIMS
}

D. Cisneros-Lazaro ${ }^{*}$, A. Adamsı, J. Guo1, L. P. Baumgartner2, S. Bernard3, D. Daval4, A. Baronnet5, O. Grauby5, T. Vennemann2, J. Stolarski6, A. Meibomı,2

1Ecole Polytechnique Fédérale de Lausanne, Switzerland (*correspondance: deyanira.cisneroslazaro@epfl.ch) ${ }_{2}$ University of Lausanne, Switzerland 3CNRS/Museum National d'Histoire Naturelle, Paris, France ${ }_{4}$ University of Strasbourg, France

${ }_{5} \mathrm{CINaM}$, Marseille, France

6Polish Academy of Sciences, Warsaw, Poland

Fossil foraminifera used for paleoclimate reconstructions are selected with the assumptions that recrystallization can be recognized optically (i.e., 'frosty' vs. 'glassy') or with SEM, and that glassy tests have preserved pristine chemical and isotopic compositions. We tested these assumptions with experiments exposing calcitic tests of two modern foraminifera (Ammonia sp. and Amphistegina lessonii) to, e.g., temperatures of $90{ }^{\circ} \mathrm{C}$ for 6 days in $18 \mathrm{O}$-enriched artificial seawater $\left(\delta_{18} \mathrm{Ovsmow}=150000 \%\right)$. Subsequent optical, SEM, TEM, and NanoSIMS imaging visualized and quantitatively compared the diagenetic alterations. Reacted samples appeared absolutely pristine (i.e., glassy) and texturally indistinguishable from unreacted samples, even when observed in SEM. However, average $18 \mathrm{O}$-enrichment (measured by NanoSIMS) in tests of reacted forams were between 200-500\% for Ammonia and 500-800\% for Amphistegina, demonstrating pervasive water penetration, isotopic exchange and species-dependent susceptibility to diagenesis. In addition, NanoSIMS images revealed the primary pathways for water penetration, which are strikingly correlated with test ultrastructure as observed by SEM and TEM. Together, these observations show how diagenesis proceeds in calcitic foraminifera and refute the assumption that visual or SEM observations of fossil tests used for paleoreconstruction are sufficient to assess whether a given sample is isotopically or chemically pristine. 